\title{
Association Between Asymmetry in Knee Extension Strength and Balance in a Community-Dwelling Elderly Population: A Cross-Sectional Analysis
}

\author{
Jinmann Chon, $\mathrm{MD}, \mathrm{PhD}^{1}$, Hee-Sang Kim, MD, $\mathrm{PhD}^{1}$, Jong Ha Lee, MD, $\mathrm{PhD}^{1}$, \\ Seung Don Yoo, $\mathrm{MD}, \mathrm{PhD}^{2}$, Dong Hwan Yun, $\mathrm{MD}, \mathrm{PhD}^{1}$, Dong Hwan Kim, $\mathrm{MD}, \mathrm{PhD}^{2}$, \\ Seung Ah Lee, $\mathrm{MD}, \mathrm{PhD}^{2}$, Yoo Jin Han, $\mathrm{MD}, \mathrm{PhD}^{1}$, Yunsoo Soh, $\mathrm{MD}^{1}$, Yong Kim, $\mathrm{MD}^{1}$, \\ Young Rok Han, $\mathrm{MD}^{1}$, Chang Won Won, $\mathrm{MD}, \mathrm{PhD}^{3}$, Seonyoung Han, $\mathrm{MD}^{1}$
}

${ }^{1}$ Department of Rehabilitation Medicine, Kyung Hee University Hospital, Seoul; ${ }^{2}$ Department of Rehabilitation Medicine, Kyung Hee University Hospital at Gangdong, Seoul; ${ }^{3}$ Department of Family Medicine, Kyung Hee University Hospital, Seoul, Korea

Objective To evaluate the association between balance function and asymmetry of knee extension strength in an elderly Korean population.

Methods The strength of the knee extensors in each leg was measured in 306 community-dwelling elderly subjects (age, $76.70 \pm 4.85$ years) and 25 young healthy subjects (age, $34.23 \pm 8.93$ years). Based on the difference in strength of both legs, the elderly subjects were divided into symmetric $(n=128)$ and asymmetric $(n=178)$ strength groups using an asymmetry cutoff $20 \%$. We determined the postural control ability of the subjects using InBody posturography, Berg Balance Scale (BBS), Timed Up and Go test (TUG) and Short Physical Performance Battery (SPPB). The sway index (SI) of the subjects in four positions was assessed using posturography.

Results The group with asymmetric strength presented a significantly higher SI than the group with symmetric strength, in the normal position with eyes open and eyes open on pillows. In the normal position with the eyes closed and in postures with the eyes closed on pillows, the statistical analysis revealed no significant differences between the two groups. The three tests for physical performance (BBS, TUG, and SPPB) show no statistically significant difference between the two groups.

Conclusion The asymmetric strength group showed a significantly lower balance than the group with symmetric strength based on several posturographic parameters. Ambulatory elderly individuals with asymmetry in knee extension strength, showed deficits in balance control even in normal clinical tests.

Keywords Elderly, Postural asymmetry factor, Postural balance, Accidental falls

Received March 29, 2017; Accepted June 15, 2017

Corresponding author: Seonyoung Han

Department of Rehabilitation Medicine, Kyung Hee University Hospital, 23 Kyungheedae-ro, Dongdaemun-gu, Seoul 02447, Korea. Tel: +82-2-9588565, Fax: +82-2-958-8560, E-mail: rememberme85@naver.com

ORCID: Jinmann Chon (http://orcid.org/0000-0002-4186-6623); Hee-Sang Kim (http://orcid.org/0000-0003-4985-0594); Jong Ha Lee (http://orcid. org/0000-0002-7627-6543); Seung Don Yoo (http://orcid.org/0000-0003-4513-2560); Dong Hwan Yun (http://orcid.org/0000-0003-1800-319X); Dong Hwan Kim (http://orcid.org/0000-0002-3812-5509); Seung Ah Lee (http://orcid.org/0000-0002-3426-6259); Yoo Jin Han (http://orcid.org/0000-00033256-9931); Yunsoo Soh (http://orcid.org/0000-0001-8368-4900); Yong Kim (http://orcid.org/0000-0003-0950-3774); Young Rok Han (http://orcid. org/0000-0002-1680-5802); Chang Won Won (http://orcid.org/0000-0002-6429-4461); Seonyoung Han (http://orcid.org/0000-0002-2218-8150).

@ This is an open-access article distributed under the terms of the Creative Commons Attribution Non-Commercial License (http://creativecommons.org/ licenses/by-nc/4.0) which permits unrestricted noncommercial use, distribution, and reproduction in any medium, provided the original work is properly cited. Copyright $\odot 2018$ by Korean Academy of Rehabilitation Medicine 


\section{INTRODUCTION}

Physical abilities, including balance function, are impaired with increasing age [1]. Many studies have reported that poor balance is a major risk factor for falls in elderly individuals [2]. Asymmetry of lower extremity has been shown to increase with age. Carabello et al. [3] demonstrated that elderly individuals had a greater asymmetry in knee extensor strength (approximately 15\%) than middle-aged adults (10\%). Comparison of elderly individuals with limited mobility with those showing normal mobility, revealed a greater asymmetry in knee extensor strength in individuals with limited mobility (21\% vs. $12 \%)$. Furthermore, strength asymmetry appears to be greater in elderly sustaining falls than in those without falls [4]. The mechanism by which asymmetry of the lower extremity decreases balance is unknown. Nakao et al. [5] reported that the difference in strength between the right and left lower extremities affected the walking step irregularity and decreased the strength of the supporting foot. All of these factors diminish the balance function.

Clinical balance evaluation tools, such as the Berg Balance Scale (BBS), Timed Up and Go test (TUG), and Short Physical Performance Battery (SPPB), reported increased reliability between test-retests and intraclass correlation $[6,7]$. However, these assessment tools can be subjective depending on the examiner or the examinee and have limitations associated with evaluation of various factors that affect balance control [7]. Recently, balance control abilities have been assessed using static or dynamic posturography. Posturography enables quantitative evaluation of balance control by measuring the postural sway according to changes in the visual, vestibular, and somatic sensory systems.

The purpose of this study was to investigate the association between balance control and asymmetric strength of knee extension in a sample of community-dwelling elderly population.

\section{MATERIALS AND METHODS}

\section{Subjects}

This cross-sectional study included 306 communitydwelling elderly individuals aged 65-92 years living independently in the community. The elderly participants were recruited through an advertisement at Dongdae- mun-gu Public Health Center in Seoul, Korea from May 2014 to April 2015. The exclusion criteria were: inability to comprehend and follow instructions or a Mini-Mental State Examination (MMSE) score <23; known acute illnesses, current or recent fractures, ear infections, or vestibular disorders; use of drugs that affect muscle strength and balance; inability to maintain the shoulder at $90^{\circ}$ flexion; unstable chronic diseases, such as unstable diabetes mellitus and uncompensated heart failure; malignancy and musculoskeletal disorders; and neurological problems, such as Parkinson disease and stroke. All the participants were able to follow directions, respond appropriately to the survey questions, and participate in the interview process without assistance. To ensure that the method used in this study reflected the decline in balance of the elderly population, we measured their posturography values and compared with those of 25 healthy young subjects. Before participating in the study, all participants provided written informed consent by signing a form that summarized the purpose of the study, explained the risks and adverse effects, indicated confidentiality of information, and assured the participants of their right to withdraw at any time. The study received the appropriate Institutional Review Board of Kyung Hee University Hospital (No. KHUHMDIRB 1503-02) approval.

\section{Data collection}

The health assessment used self-administered questionnaires, and interviews were conducted by trained staff. A standardized questionnaire covering basic demographic data, fall history, medical comorbidities, and current medication usage was sent to each participant before physical examination and balance function tests. Physical examination included measurements of weight, height, body mass index (BMI), blood pressure, and the Korean version of the MMSE (K-MMSE). Knee extension strength was measured in triplicate using an isokinetic leg dynamometer (InBody Co. Ltd., Seoul, Korea) in each leg, and the maximum value was recorded. The asymmetry in knee extension strength was calculated in accordance with the equation by Carabello et al. [3] as follows:

$$
\frac{\text { Strong leg value }- \text { Weak leg value }}{\text { Strong leg value }} \times 100(\%)
$$

The elderly subjects were divided into symmetric strength $(\mathrm{n}=128)$ and asymmetric strength $(\mathrm{n}=178)$ 
groups using an asymmetry cutoff of $20 \%$ [4]. Based on the estimated value of asymmetry associated with lower extremity strength in a previous study, the bilateral difference is $5 \%-15 \%$ in the young population and $15 \%-20 \%$ in the elderly population $[8,9]$. These studies provide the basis for the $20 \%$ criterion used in the current study.

\section{Posturography}

Static posturography was conducted using the InBody posturography. The force plate of the InBody posturography is composed of four plates, and each force plate measures the perpendicular pressure of the anterior and posterior feet. The subjects removed their shoes, placed their feet on the plates, and stood in a comfortable position (Fig. 1). The pressure detectors on the standing platform detected the patterns of displacement at the center of pressure. The pressure data of each force plate bearing the burden of the standing subjects were amplified and filtered, transferred to the computer, and analyzed using the InBody software program. The postural variable factors were determined by measuring the sway index (SI). We evaluated four different postures during the test: normal posture with the eyes open (NO), normal posture with the eyes closed (NC), foam rubber pillow on the floor of the machine with the eyes open (PO), and pillow with the eyes closed (PC). Each posture was measured for 32 seconds. Body sway during standing includes sway in lateral $(x)$ and anterior-posterior (y) directions. To calculate the sway index, the subject's center of pressure was used as coordinates before starting the test, and reset to the reference point ( $x$ ref, $y$ ref). The change in center of pressure coordinates from the reference point was measured in pixels, centimeters $(\mathrm{cm})$, kilograms $(\mathrm{kg})$. The distance of center of pressure from the reference point was displayed in pixels on the screen, and the distance of movement was expressed in $\mathrm{cm}$. In addition, the pressure was expressed in $\mathrm{kg}$, as the change in pressure might also be meaningful in evaluating the sway. The sway is calculated in real time as the difference between reference point and center of the pressure projection on the screen as follows:

$$
\sqrt{(x-x \text { ref })^{2}-(y-y \text { ref })^{2}}
$$

and its standard deviation is expressed as SI. The SI is a variable that indicates the degree of postural sway, which therefore represents the overall stability and ability to compensate for postural changes. A higher index indicates greater postural instability [7].

\section{Physical performance tests \\ Berg Balance Scale}

The BBS is a balance assessment tool during functional activities of daily living; these activities are scored from 0 to 4 ( $0=$ worst performance and $4=$ best performance for independence tasks). The maximum total score is 56 points. A lower score suggests instability [7].

\section{Timed Up and Go test}

The TUG test is a measure of functional mobility in elderly population. The participants were instructed to sit on a chair (seat height $=46 \mathrm{~cm}$, armrest height $=65 \mathrm{~cm}$ ) placed against the wall. They were also instructed to stand, walk at their normal pace on a 3-m pathway, turn at the marked endpoint, walk back on the determined pathway, and sit on the chair. The participants were not

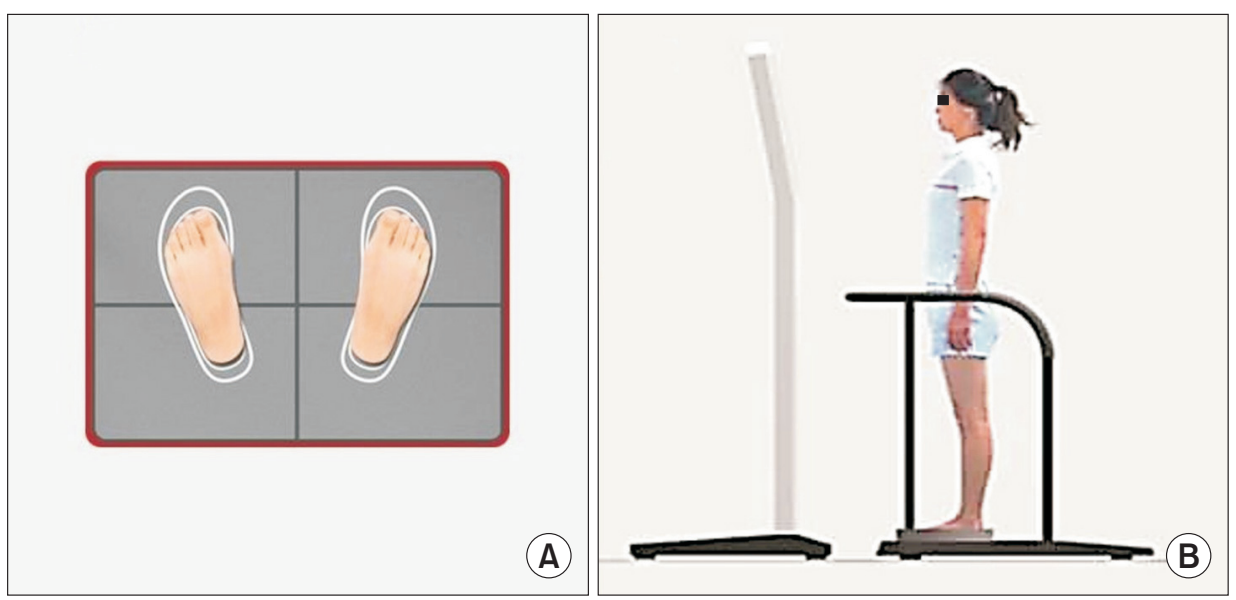

Fig. 1. Posturography and posture settings. (A) The force plate of the InBody posturography is composed of four plates, and each force plate measures the perpendicular pressure of the anterior and posterior feet. (B) The subjects removed their shoes, placed their feet on the plates, and stood in a comfortable position. 
provided with any assistance and performed sessions with adequate rest between the tests. The mean of the three scores represented the TUG test score [7].

\section{Short Physical Performance Battery}

The SPPB is a composite outcome measure of lower limb function, including strength, endurance, gait, and balance [10]. The SPPB comprises three tests including: a hierarchical assessment of standing balance, short walk at the usual pace of elderly individuals, and standing five times from a seated position in a chair. For balance assessment, the participants were asked to remain standing with their feet as close together as possible, then in a semi-tandem position, and finally in a tandem position. Each position was supposed to be maintained for $10 \mathrm{sec}-$ onds. For gait speed, the time required to travel $4 \mathrm{~m}$ at the usual pace was measured. This test was repeated twice, and the shorter time period was used for analysis. In the standing test, the participants were asked to stand and sit on a chair five times as quickly as they could, with their arms crossed over the chest. This test was performed only after the elderly subjects demonstrated their ability to stand without using their arms. Previous studies showed that the SPPB predicted disability, institutionalization, falls, and mortality among the elderly individuals [10-13]. A score ranging from 0 to 4 ( $0=$ inability to complete the task; 4=highest level of function) was assigned for each task in the SPPB, with the sum of the three tests providing the complete measure of physical function [10].

\section{Statistical analysis}

Data were analyzed using the Statistical Package for the Social Sciences (SPSS) version 13.0 for Windows (SPSS Inc., Chicago, IL, USA). The baseline characteristics and balance control abilities were determined by posturography using the InBody, BBS, TUG, and SPPB tests, which were administered to the asymmetric and the symmetric groups, and analyzed using independent t-tests. Results with $p$-values $<0.05$ were considered statistically significant.

\section{RESULTS}

\section{Baseline characteristics}

The study population consisted of 94 male and $212 \mathrm{fe}$ male subjects with a mean age of $76.70 \pm 4.85$ years. Of the 306 participants, 178 (58.2\%) showed asymmetry of the knee extension force. The mean K-MMSE score and BMI were $26.25 \pm 2.49$ and $28.2 \pm 4.7 \mathrm{~kg} / \mathrm{m}^{2}$, respectively. The young subjects included 16 male and 9 female subjects with a mean age of $34.23 \pm 8.93$ years.

Table 1 summarizes the baseline characteristics of the symmetric and asymmetric strength groups of elderly subjects. The statistical analyses of the baseline data revealed no significant differences between the two groups ( $\mathrm{p}>0.05)$.

\section{Posturography}

Table 2 summarizes the SI obtained using posturogra-

Table 1. Baseline demographic and clinical characteristics of SS and SA groups $(n=306)$

\begin{tabular}{lccc}
\hline \multicolumn{1}{c}{ Variable } & SS (n=128) & SA (n=178) & p-value \\
\hline Age (yr) & $76.99 \pm 4.71$ & $76.29 \pm 5.01$ & 0.151 \\
Sex (male:female) & $37: 91$ & $57: 121$ & 0.211 \\
Difference in the knee extension strength $(\mathrm{kg})$ & $1.34 \pm 0.99$ & $5.31 \pm 2.75$ & $0.001^{*}$ \\
Systolic BP (mmHg) & $133.91 \pm 7.81$ & $133.15 \pm 8.41$ & 0.420 \\
Diastolic BP (mmHg) & $74.76 \pm 8.49$ & $75.45 \pm 7.96$ & 0.469 \\
K-MMSE & $26.28 \pm 2.46$ & $26.24 \pm 2.59$ & 0.891 \\
Height $(\mathrm{cm})$ & $155.07 \pm 8.10$ & $153.13 \pm 14.50$ & 0.335 \\
Weight $(\mathrm{kg})$ & $58.10 \pm 8.61$ & $60.27 \pm 8.51$ & 0.739 \\
BMI $\left(\mathrm{kg} / \mathrm{m}^{2}\right)$ & $24.10 \pm 3.22$ & $25.33 \pm 3.08$ & 0.092 \\
\hline
\end{tabular}

Values are presented as mean \pm standard deviation.

SS, symmetric strength; SA, asymmetric strength; BP, blood pressure; K-MMSE, Korean-Mini Mental State Examination; BMI, body mass index.

Difference in the knee extension strength=strong leg value-weak leg value.

${ }^{*} \mathrm{p}<0.05$. 
Table 2. Sway index of the elderly and young groups

\begin{tabular}{lccc}
\hline \multicolumn{1}{c}{ Position } & Elderly $(\mathbf{n}=\mathbf{3 0 6})$ & Young $(\mathbf{n}=\mathbf{2 5})$ & p-value \\
\hline NO (pixel) & $10.82 \pm 4.85$ & $6.31 \pm 2.40$ & $0.001^{*}$ \\
NO (cm) & $0.29 \pm 0.13$ & $0.17 \pm 0.63$ & $0.001^{*}$ \\
NO (kg) & $0.04 \pm 0.16$ & $0.02 \pm 0.09$ & $0.001^{*}$ \\
NC (pixel) & $16.03 \pm 6.54$ & $11.14 \pm 3.32$ & $0.001^{*}$ \\
NC (cm) & $0.42 \pm 0.17$ & $0.29 \pm 0.09$ & $0.001^{*}$ \\
NC (kg) & $0.05 \pm 0.02$ & $0.04 \pm 0.01$ & $0.001^{*}$ \\
PO (pixel) & $12.27 \pm 4.89$ & $8.09 \pm 2.98$ & $0.001^{*}$ \\
PO (cm) & $0.32 \pm 0.13$ & $0.21 \pm 0.79$ & $0.001^{*}$ \\
PO (kg) & $0.04 \pm 0.02$ & $0.03 \pm 0.01$ & $0.001^{*}$ \\
PC (pixel) & $25.45 \pm 9.37$ & $20.32 \pm 7.42$ & $0.007^{*}$ \\
PC (cm) & $0.67 \pm 0.25$ & $0.54 \pm 0.20$ & $0.007^{*}$ \\
PC (kg) & $0.08 \pm 0.03$ & $0.07 \pm 0.02$ & $0.008^{*}$ \\
\hline
\end{tabular}

Values are presented as mean \pm standard deviation. Young group, aged $<40$ years; Elderly group, aged $\geq 65$ years; NO, normal position with eyes open; NC, normal position with eyes closed; PO, eyes open on pillows; PC, eyes closed on pillows.

${ }^{*} \mathrm{p}<0.05$.

phy of the elderly and young groups. The elderly group showed a significantly higher SI than the young subjects in all postures $(\mathrm{p}<0.05)$. Table 3 compares the SIs by dividing the elderly into symmetric and asymmetric strength groups. The asymmetric strength group had a significantly higher SI than the symmetric strength group in the NO and PO postures $(\mathrm{p}<0.05)$. In the NC and PC postures, the statistical analysis revealed no significant differences between the two groups ( $p>0.05)$.

\section{Physical performance tests}

Table 4 summarizes the results of the three physical performance tests (BBS, TUG, and SPPB) of the symmetric and asymmetric elderly groups. Statistical analyses of the three physical performance tests revealed no significant differences between the two groups ( $p>0.05$ ).

\section{DISCUSSION}

The rate of population aging in Korea is on a very steep rise. According to the world population projections by the United Nations, the percentage of the population aged $\geq 60$ years is predicted to increase from $13.7 \%$ in 2015 to $28.6 \%$ by 2050 . With rapid aging, issues associated with aging will continue to be the focus of attention. Several
Table 3. Sway index of the SS and SA groups $(n=306)$

\begin{tabular}{lrrl}
\hline Position & SS $(\mathbf{n}=\mathbf{1 2 8})$ & SA $(\mathbf{n}=\mathbf{1 7 8})$ & p-value \\
\hline NO (pixel) & $10.32 \pm 4.47$ & $11.45 \pm 5.24$ & $0.043^{*}$ \\
NO (cm) & $0.27 \pm 0.12$ & $0.30 \pm 0.14$ & $0.046^{*}$ \\
NO (kg) & $0.03 \pm 0.01$ & $0.04 \pm 0.02$ & $0.014^{*}$ \\
NC (pixel) & $12.68 \pm 6.15$ & $16.47 \pm 6.89$ & 0.294 \\
NC (cm) & $0.41 \pm 0.16$ & $0.44 \pm 0.18$ & 0.289 \\
NC (kg) & $0.05 \pm 0.02$ & $0.06 \pm 0.02$ & 0.134 \\
PO (pixel) & $11.49 \pm 4.31$ & $13.25 \pm 5.38$ & $0.002^{*}$ \\
PO (cm) & $0.30 \pm 0.11$ & $0.35 \pm 0.14$ & $0.002^{*}$ \\
PO (kg) & $0.04 \pm 0.01$ & $0.04 \pm 0.02$ & $0.004^{*}$ \\
PC (pixel) & $25.57 \pm 8.90$ & $25.30 \pm 9.95$ & 0.807 \\
PC (cm) & $0.68 \pm 0.24$ & $0.67 \pm 0.26$ & 0.812 \\
PC (kg) & $0.09 \pm 0.03$ & $0.08 \pm 0.32$ & 0.849 \\
\hline
\end{tabular}

Values are presented as mean \pm standard deviation.

SS, symmetric strength; SA, asymmetric strength; NO, normal position with eyes open; NC, normal position with eyes closed; PO, eyes open on pillows; PC, eyes closed on pillows.

${ }^{*} \mathrm{p}<0.05$.

Table 4. Physical performance test scores of the SS and SA groups ( $\mathrm{n}=306)$

\begin{tabular}{lccc}
\hline Variable & SS $(\mathbf{n}=\mathbf{1 2 8})$ & SA $(\mathbf{n}=\mathbf{1 7 8})$ & p-value \\
\hline BBS & $52.79 \pm 3.60$ & $52.47 \pm 3.67$ & 0.439 \\
TUG (s) & $13.72 \pm 3.46$ & $11.13 \pm 2.27$ & 0.396 \\
SPPB & $9.83 \pm 1.81$ & $4.42 \pm 1.94$ & 0.057 \\
\hline
\end{tabular}

Values are presented as mean \pm standard deviation.

SS, symmetric strength; SA, asymmetric strength; BBS, Berg Balance Scale; TUG, Timed Up and Go test; SPPB, Short Physical Performance Battery.

studies have investigated the poor balance control and prevention of falls in the elderly $[14,15]$.

In the present study, we investigated the association between balance control and asymmetry of knee extension strength in a sample of community-dwelling elderly population. The asymmetric strength group had a significantly lower balance function than the symmetric strength group, based on several posturographic parameters. Results of the three physical performance tests (BBS, TUG, and SPPB) in both groups showed no statistically significant difference.

Posturography is a quantitative tool for the measurement of balance status and evaluation of postural stability and response. The results were obtained through com- 
puterized electronic signals emitted by the four footplates at each heel and toe. We measured the role of visual, somatic sensory, vestibular, and motor and central nervous systems in the stability of study population. The NO posture is a neutral posture. The NC posture emphasizes the effects of somatic sensory or vestibular system by limiting the role of the visual system. In the PO posture, the pillows limit the effect of somatic sense, thus emphasizing the role of visual or vestibular system. The PC posture emphasizes the role of vestibular system by limiting the effects of visual and somatic senses. The SI is a quantitative measure of postural sway based on changes in the center of pressure [7]. In this study, there was a significant increase in the SI associated with all postures in the elderly group compared with the younger group, which suggests that the balance declined significantly in the elderly group. Within the elderly group, the SI increased with the limitation of the visual input (NC) or somatosensory input (PO) compared to the neutral position (NO) in each group. Further increases involved the limitations of visual and somatosensory inputs (PC). Comparison of the two groups showed that the asymmetric group had a significantly higher SI than the symmetric group in the NO and PO postures. The significant difference between the two groups in the NO posture indicated that the knee extensor asymmetry degraded the balance function. Similar result was obtained when the somatosensory input was limited by standing on the rubber pillow. Therefore, asymmetry of knee extension strength may be an additional risk factor for falls in the elderly population.

However, interestingly, there were no significant differences between the two groups with the eyes closed. Several studies reported that the visual systems play a critical role in balance control of the elderly population. Hytonen et al. [16] showed that visual input played a crucial role in the postural control of elderly individuals whereas the proprioception and plantar skin pressoreceptor influx were significantly reduced, undermining their role in controlling the body sway. In the position with the eyes closed, the small difference due to knee extensor asymmetry could not be reflected since vast reduction in balance control ability occurred due to loss of visual input.

The statistical analysis of the three physical performance tests revealed no significant differences between symmetric and asymmetric strength groups. The BBS, TUG, and SPPB tests are widely used as clinical assess- ment tools of balance control; however, they may be difficult to apply in cases involving minor loss of balance control.

Strength asymmetry may be caused by limb dominance or unilateral pathology, such as previous musculoskeletal injuries or joint pain $[4,17,18]$. Based on our study results, we recommend that the clinical assessment of strength asymmetry in elderly is essential to identify individuals at a potential risk of falls or limited mobility. Resistance exercise programs should be designed to restore strength symmetry, possibly through unilateral exercise targeting the weak side.

There were limitations in this study. First, this was a cross-sectional survey; thus, the results must be interpreted carefully. Second, the present analyses failed to include other potential correlates or confounders. Before starting the study, we used self-administered questionnaires to exclude subjects who were diagnosed and treated for conditions that potentially affected muscle strength and balance. However, subjects who did not have a diagnosis but had the disease were still allowed to participate in this study. In addition to motor weakness, neuromuscular diseases that affect sensory and proprioception induce asymmetry. These effects were reflected in the results. Third, since the InBody posturography generally evaluates stability under static conditions, it is difficult to apply the results to balance control problems in dynamic conditions.

Several previous studies reported that lower extremity asymmetry is associated with gait disability or fall $[4,9,19]$. However, to our knowledge, this is the first study to evaluate the association between asymmetry of knee extension strength and balance function using physical performance tests and quantitative posturography. The most important finding relates to the quantitative evaluation of the association between balance function and asymmetry.

Ambulatory elderly subjects with knee extension strength asymmetries measured by posturographic parameters showed greater deficits in balance control, even in normal clinical balance tests. The findings of this study indicate that knee extension strength asymmetry may be an additional risk factor for falls in ambulatory elderly populations. Therefore, appropriate evaluation for asymmetry and educational interventions aimed at preventing falls would be desirable in ambulatory elderly populations. 


\section{CONFLICT OF INTEREST}

No potential conflict of interest relevant to this article was reported.

\section{REFERENCES}

1. Steffen TM, Hacker TA, Mollinger L. Age- and genderrelated test performance in community-dwelling elderly people: Six-Minute Walk Test, Berg Balance Scale, Timed Up \& Go Test, and gait speeds. Phys Ther 2002;82:128-37.

2. Grisso JA, Kelsey JL, O'Brien LA, Miles CG, Sidney S, Maislin G, et al. Risk factors for hip fracture in men. Hip Fracture Study Group. Am J Epidemiol 1997;145: 786-93.

3. Carabello RJ, Reid KF, Clark DJ, Phillips EM, Fielding RA. Lower extremity strength and power asymmetry assessment in healthy and mobility-limited populations: reliability and association with physical functioning. Aging Clin Exp Res 2010;22:324-9.

4. Laroche DP, Cook SB, Mackala K. Strength asymmetry increases gait asymmetry and variability in older women. Med Sci Sports Exerc 2012;44:2172-81.

5. Nakao H, Yoshikawa T, Mimura T, Hara T, Nishimoto K, Fujimoto S. Influence of lower-extremity muscle force, muscle mass and asymmetry in knee extension force on gait ability in community-dwelling elderly women. J Phys Ther Sci 2006;18:73-9.

6. Shumway-Cook A, Brauer S, Woollacott M. Predicting the probability for falls in community-dwelling older adults using the Timed Up \& Go Test. Phys Ther 2000; 80:896-903.

7. Kim HS, Yun DH, Yoo SD, Kim DH, Jeong YS, Yun JS, et al. Balance control and knee osteoarthritis severity. Ann Rehabil Med 2011;35:701-9.

8. Perry MC, Carville SF, Smith IC, Rutherford OM, Newham DJ. Strength, power output and symmetry of leg muscles: effect of age and history of falling. Eur J Appl Physiol 2007;100:553-61.

9. Skelton DA, Kennedy J, Rutherford OM. Explosive power and asymmetry in leg muscle function in frequent fallers and non-fallers aged over 65. Age Ageing 2002;31:119-25.
10. Guralnik JM, Seeman TE, Tinetti ME, Nevitt MC, Berkman LF. Validation and use of performance measures of functioning in a non-disabled older population: MacArthur studies of successful aging. Aging (Milano) 1994;6:410-9.

11. Ostir GV, Volpato S, Fried LP, Chaves P, Guralnik JM; Women's Health and Aging Study. Reliability and sensitivity to change assessed for a summary measure of lower body function: results from the Women's Health and Aging Study. J Clin Epidemiol 2002;55:916-21.

12. Perera S, Mody SH, Woodman RC, Studenski SA. Meaningful change and responsiveness in common physical performance measures in older adults. J Am Geriatr Soc 2006;54:743-9.

13. Quadri P, Tettamanti M, Bernasconi S, Trento F, Loew F. Lower limb function as predictor of falls and loss of mobility with social repercussions one year after discharge among elderly inpatients. Aging Clin Exp Res 2005;17:82-9.

14. Gardner MM, Robertson MC, Campbell AJ. Exercise in preventing falls and fall related injuries in older people: a review of randomised controlled trials. $\mathrm{Br} \mathrm{J}$ Sports Med 2000;34:7-17.

15. Barnett A, Smith B, Lord SR, Williams M, Baumand A. Community-based group exercise improves balance and reduces falls in at-risk older people: a randomized controlled trial. Age Ageing 2003;32:407-14.

16. Hytonen M, Pyykko I, Aalto H, Starck J. Postural control and age. Acta Otolaryngol 1993;113:119-22.

17. Lanshammar K, Ribom EL. Differences in muscle strength in dominant and non-dominant leg in females aged 20-39 years: a population-based study. Phys Ther Sport 2011;12:76-9.

18. Suetta C, Aagaard P, Magnusson SP, Andersen LL, Sipila S, Rosted A, et al. Muscle size, neuromuscular activation, and rapid force characteristics in elderly men and women: effects of unilateral long-term disuse due to hip-osteoarthritis. J Appl Physiol (1985) 2007;102: 942-8.

19. Portegijs E, Sipila S, Pajala S, Lamb SE, Alen M, Kaprio J, et al. Asymmetrical lower extremity power deficit as a risk factor for injurious falls in healthy older women. J Am Geriatr Soc 2006;54:551-3. 